\title{
Curriculum Reform of Science in Elementary Schools in China
}

\author{
Wenjie Pei \\ College of Teacher Education, Zhejiang Normal University \\ peiwenjierg84@sina.com
}

\begin{abstract}
In January 2017, the Chinese Ministry of Education issued the Curricular Standards of Science in Elementary Schools, aiming at developing students' scientific literacy and a foundation for their learning and development as competent citizens. To achieve its overall goal, the reform reflects four main strategies: extending the learning time of science education, integrating engineering and technological contents into science subject, phased design based on the idea of learning progressions, and using big concepts to guide teaching contents. The Curricular Standards of Science in Elementary Schools has been implemented in major provinces and cities across the country and achieved initial outcomes in stimulating students' enthusiasm for learning science. To better implement these standards, increasing capital investment, improving experiments, and upgrading equipment become urgent to be considered.
\end{abstract}

\section{Keywords}

China - elementary schools - science - curriculum standards - reform

\section{Introduction $^{1}$}

The world is in a new round of technology and industrial development, which plays a prominent role in societal and economic transformation. Countries all over the world are actively promoting STEM education, fusing science,

1 This article is co-authored with Sihui Zheng (College of Economics and Management, Zhejiang Normal University) and Xuejie Zhang (College of Plant Protection, Shandong 
technology, engineering, mathematics and other disciplines. China is facing a serious shortage of scientific and technological workers, according to a 2013 report by the McKinsey Global Institute that China will face a shortage of 22 million engineering and technical workers in 2020, most of which are high-end workers in the field of computers and networks (as cited in Qiu et al., 2014). In April 2017, the Ministry of Science and Technology issued the 13th five-year national plan for the development of scientific and technological talent and pointed out that "structural contradictions in China's scientific and technological talent market are still prominent, and there is a large supply gap between high-level workers, high-end R \& D personnel and highly skilled workers in frontier areas" (The Ministry of Science and Technology, 2017, April 13).

With this notion, in January 2017 the Ministry of Education (MOE) issued the Curricular Standards of Science in Elementary Schools (cscEs hereafter), which listed STEM education for the first time as one of the important areas of the "new curricular standards".

2

The Initiative

The $\csc$ s expects that the science subject of elementary schools is for all students, advocating inquiry learning, protecting students' curiosity and emphasizing the subjectivity of students. Its overall goal is to develop students' scientific literacy and lay a solid foundation for their learning and development as competent citizens and lifelong growth. Based on the age characteristics and cognitive stages of elementary students, the CCECES classifies the six years of elementary schools into three phases: Grade $1-2,3^{-4}$ and $5^{-6}$, covering four aspects of scientific knowledge, scientific inquiry, scientific attitude, and science, technology, society and environment. Each aspect is divided into general and phased goals. The 18 main concepts in the fields of material science, life sciences, earth and space science, technology and engineering are divided into 75 learning modules to form the learning contents of the subject, integrated with science, technology, society and environment. The main approach of implementing science subject is through inquiry-based activities. Additionally, the CSCES proposes key suggestions on the curriculum implementation from four aspects: teaching, evaluation, textbook editing, and curricular resources development and utilization.

In order to achieve the overall goal of the CSCES, the reform of the curriculum reflects the following strategies:

Agricultural University), and supported by a research project funded by the African Science and Technology Research Center, Zhejiang Normal University. 


\subsection{Extending the Learning Time of Science Education}

The most significant change in the CSCES is to start it earlier in elementary schools from the current Grade Three to Grade One, i.e., adding science classes in the first and second grades of elementary schools. It is now considered that the science curriculum's extention of the learning time in elementary schools conforms to the international trend of science education and lays a solid foundation for the improvement of scientific literacy in China.

\subsection{Integrating Engineering and Technological Contents into Science Subject}

The CSCEs incorporates engineering and technological contents into science subject and define them as an independent field of learning for students. The CSCES indicates that the learning of technology and engineering can give students the opportunity to synthesize all aspects of knowledge and to experience the impact of science and technology on personal life and social development. Technology and engineering activities enable students to experience the success and fun of "doing" and develop the habit of solving problems through "doing". To this end, the integration of engineering and technical content into the science subject not only increases the pace of STEM education in China, but also deepens the understanding of scientific knowledge and promotes the fun of learning by doing.

\subsection{Phased Design Based on the Idea of Learning Progressions}

Learning progressions is a major paradigm of science education in the 21st century and its essence is the reflection of the developmental process of thinking. The CSCES elaborates specific objectives for scientific knowledge, scientific inquiry, scientific attitude, and science, technology, society and environment, with each aspect having specific goals, contents and teaching instructions for Grades $1-2,3^{-4}$ and $5^{-6}$. On the basis of learning progressions, the subject objectives and contents are designed in stages, and the academic scope and depth of learning contents gradually progress from easy to difficult as students move further, providing a direct basis for teachers to teach effectively.

\subsection{Using Big Concepts to Guide Teaching Contents}

Big concepts can be understood as macro-subject ideas, referring to the highest level of ideas in this subject. The formation of a big concept can help students understand the events and phenomena in their lives and continue to influence them after finish their learning and enter the workforce. The contents of science subject is consisted of 18 major concepts: six in materials science; six in life sciences; three in earth and space sciences; and three in technology and engineering, with these main concepts organized into 75 
learning modules (The MOE, 2017, January 19). The use of big concepts to guide teaching contents aims to lead classroom teaching by focusing on students' understanding and applications of knowledge and skills, and gives students scientific knowledge far-reaching and lasting.

\section{Implementation and Initial Outcomes}

Local governments across the country have responded enthusiastically to the CSCES by the MOE and implemented it immediately, with specific strategies employed alongside the beginning of the fall in 2017. Zhejiang Province in East China is an example of such a nationwide movement. On August 7 , 2017, the Department of Education of Zhejiang Province issued a notice on the implementation of the science curriculum for the first and second grades of elementary schools, proposing that the municipal and county education bureaus should "implement the prescribed class hours", "unify selection of teaching materials", "reasonably allocate science curriculum teachers" as well as "strengthen the training of science teachers" and "introduce the science curriculum in the second year of primary school in September 2018" (The Department of Education of Zhejiang Province, 2017, August 7).

The cSCEs has been implemented for more than a year. In order to evaluate the implementation, we conducted semi-structured interviews with 18 teachers from more than ten elementary schools in Jiangsu, Zhejiang, Hubei, Sichuan and other provinces from July to September 2018. The interviews mainly focused on the question "What do you think about the achievements of the CSCES since its implementation?" Most participants confirmed that the implementation of the CSCES had stimulated students' enthusiasm for learning science. Here are a few examples of the transcripts of these interviews:

Experiments let children learn by doing, explore problems and probe into them - all these can satisfy students' curiosities and interests and stimulate their attitudes towards science. (A participant in Wuhan, Hubei)

The curiosities of students can be satisfied thus their desires of exploration are nurtured, because schools offer a special subject. Or otherwise students can only learn scientific knowledge by reading books, watching $\mathrm{TV}$, asking parents, or waiting until Grade three to learn. (A participant in Hangzhou, Zhejiang)

I have been teaching first-graders science for two months. With my teaching experience, I think that children can see the world with a scientific eye, such as the methods of "observing" tree leaves and the drawing 
methods basically involved in each lesson, training their scientific thinking. (A participant in Jinhua, Zhejiang)

Students' contracts of bit-by-bit knowledge in daily life are in fact very good. For example: bats can emit ultrasound, but it is yet unnecessary to know the specifics of ultrasound. (A participant in Chengdu, Sichuan)

Through the science curriculum to stimulate students' enthusiasm for studying science and to foster their scientific thinking is in accord with the purpose of the csces to cultivate their science literacy. With what we found, it is proved that the CSCES has initially achieved certain outcomes since its implementation.

\section{4}

\section{Conclusion}

The strategy of science curriculum reform in China is in line with the characteristics of students' physical and mental development and conforms to the trend of international science education. The promulgation and implementation of the CSCES is in response to the shortage of scientific and technological workers in China, and it marks a new stage in the reform of the science curriculum for elementary schools in China. Its implementation has stimulated the enthusiasm of elementary students to learn science, cultivating scientific literacy from a young age and enhancing science literacy of China for the further cultivation of high-level scientific and technological talents.

Of course, in the implementation process, the csCEs has also encountered dilemmas and problems such as unprepared teachers, lack of innovation in teaching, and poor uses of teaching aids. Therefore, timely measures should be considered to promote its full implementation, such as increasing funding, upgrading teaching materials and tools, cultivating teachers with innovative awareness.

\section{References}

The Department of Education of Zhejiang Province. (2017, August 7). Education of Zhejiang Province on Implementing the Science Curriculum for the First and Second Years of Primary Schools. Retrieved from http://jyt.zj.gov.cn/art/2017/8/7/ art_1532973_27485246.html. 
The Ministry of Science and Technology. (2017, April 13). Notice of the Ministry of Science and Technology on Printing and Distributing the 13th Five-Year National Science and Technology Talent Development Plan. Retrieved from: http://www.lawlib.com/law/law_view.asp?id=564584.

The MOE. (2017, January 19). Notice of the Ministry of Education on Printing and Distributing the "Compulsory Education Primary School Science Curriculum Standards". Retrieved from http://www.moe.gov.cn/srcsite/A26/s8001/201702/ t20170215_296305.html. 